Supplement of Atmos. Chem. Phys., 17, 11779-11801, 2017

https://doi.org/10.5194/acp-17-11779-2017-supplement

(c) Author(s) 2017. This work is distributed under

the Creative Commons Attribution 3.0 License.

(c) (1)

Supplement of

CCN activity and organic hygroscopicity of aerosols downwind of an urban region in central Amazonia: seasonal and diel variations and impact of anthropogenic emissions

Ryan Thalman et al.

Correspondence to: Jian Wang (jian@bnl.gov)

The copyright of individual parts of the supplement might differ from the CC BY 3.0 License. 


\section{Calibration and Operation of the CCN counter}

37 The system used to measure size-resolved CCN spectra during GoAmazon 2014/5 is shown

38 in Fig. S1, and the operation sequences of DMA classified particle diameter, $Q_{\mathrm{CCN}}$ and $\Delta T$ are

39 present in Fig. S2. The CCN counter was calibrated at each flow and temperature setting using

40 ammonium sulfate as an inorganic aerosol standard (Lance et al., 2006; Mei et al., 2013; Roberts

41 and Nenes, 2005; Shilling et al., 2007). As the temperatures at the top of the CCN counter

42 column $\left(T_{1}\right)$ varies with room temperature, the calibration was repeated for each pair of $Q_{\mathrm{CCN}}$ and

$43 \Delta T$ over a range of $T_{1}$ typically encountered during GoAmazon 2014/5. The calibration results

44 are shown as a function of $Q_{\mathrm{CCN}}$ and $\Delta T$ conditions at $T_{1}=25^{\circ} \mathrm{C}$ in Fig. S3, and the variation of

45 instrument supersaturation (SS) with respect to $T_{1}$ is present in Fig. S4. Instrument

46 supersaturation during the measurements was calculated using the $Q_{\mathrm{CCN}}, \Delta T$, and $T_{1}$ based on the

47 calibrations.

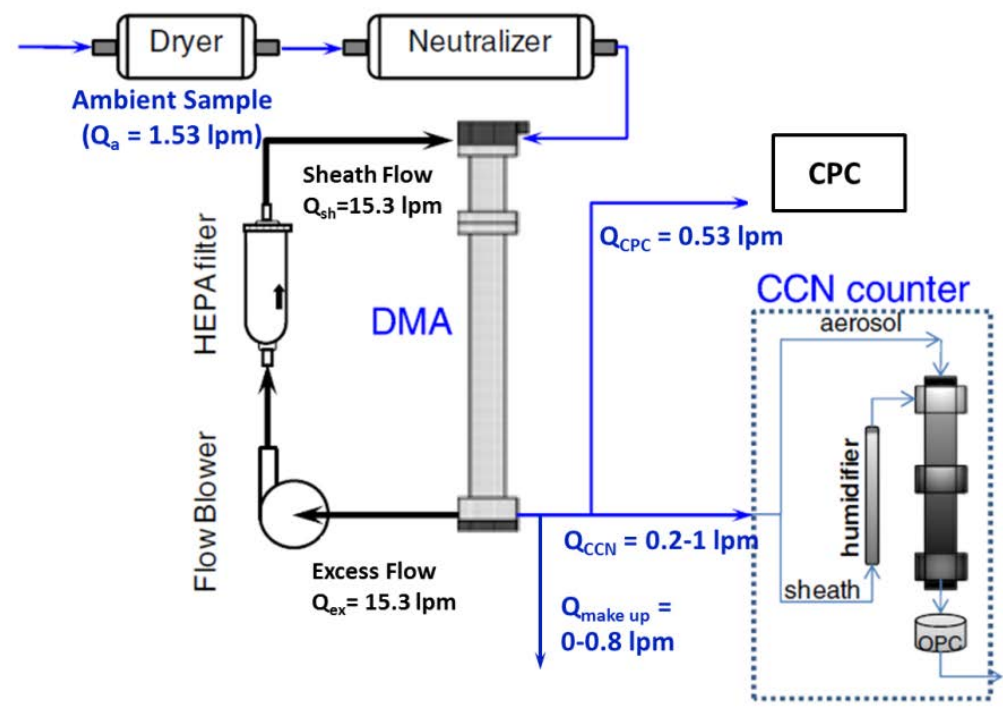

49 Figure S1: Schematic of the system for measuring size-resolved CCN spectra during GoAmazon $50 \quad 2014 / 5$. 


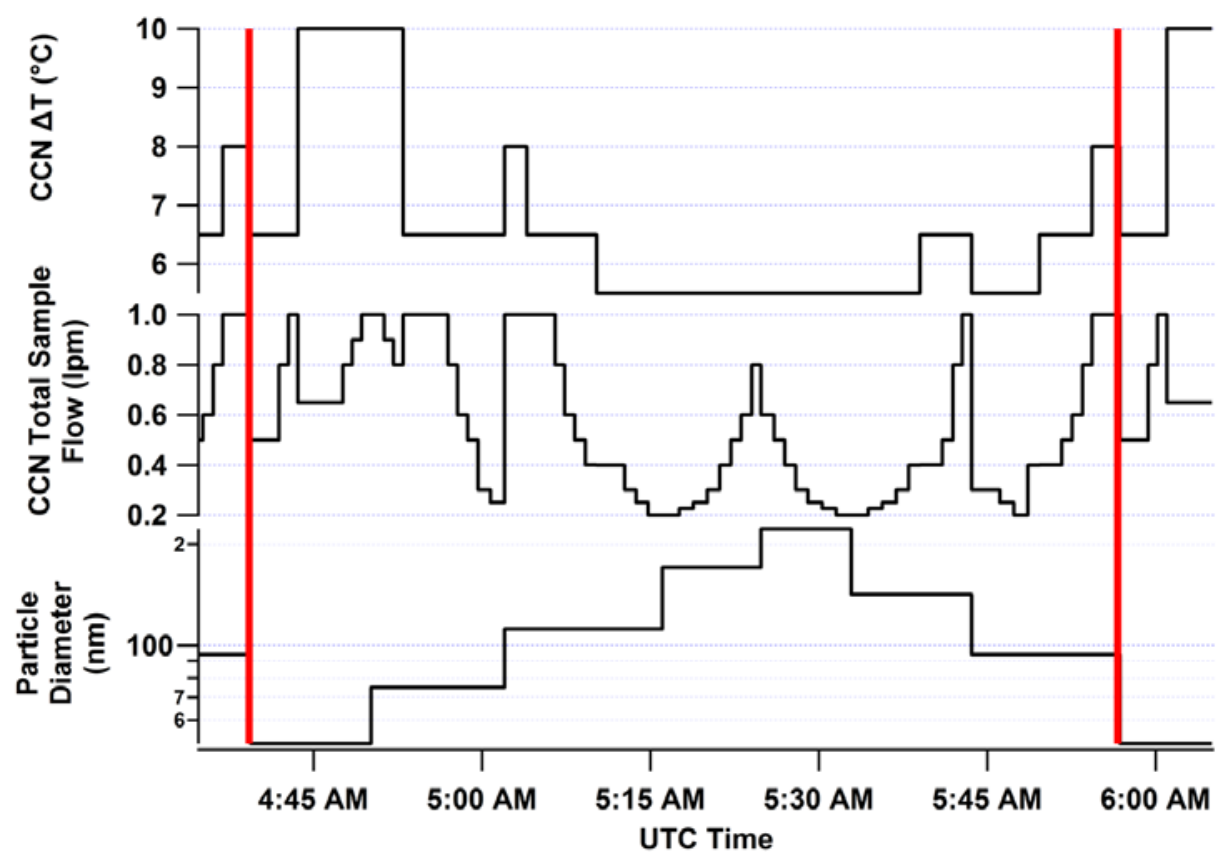

52 Figure S2: Instrument operation sequence showing set points of DMA classified particle 53 diameter, $Q_{\mathrm{CCN}}$ and $\Delta T$ for one full measurement cycle. Red vertical lines mark the start and 54 finish of one cycle.

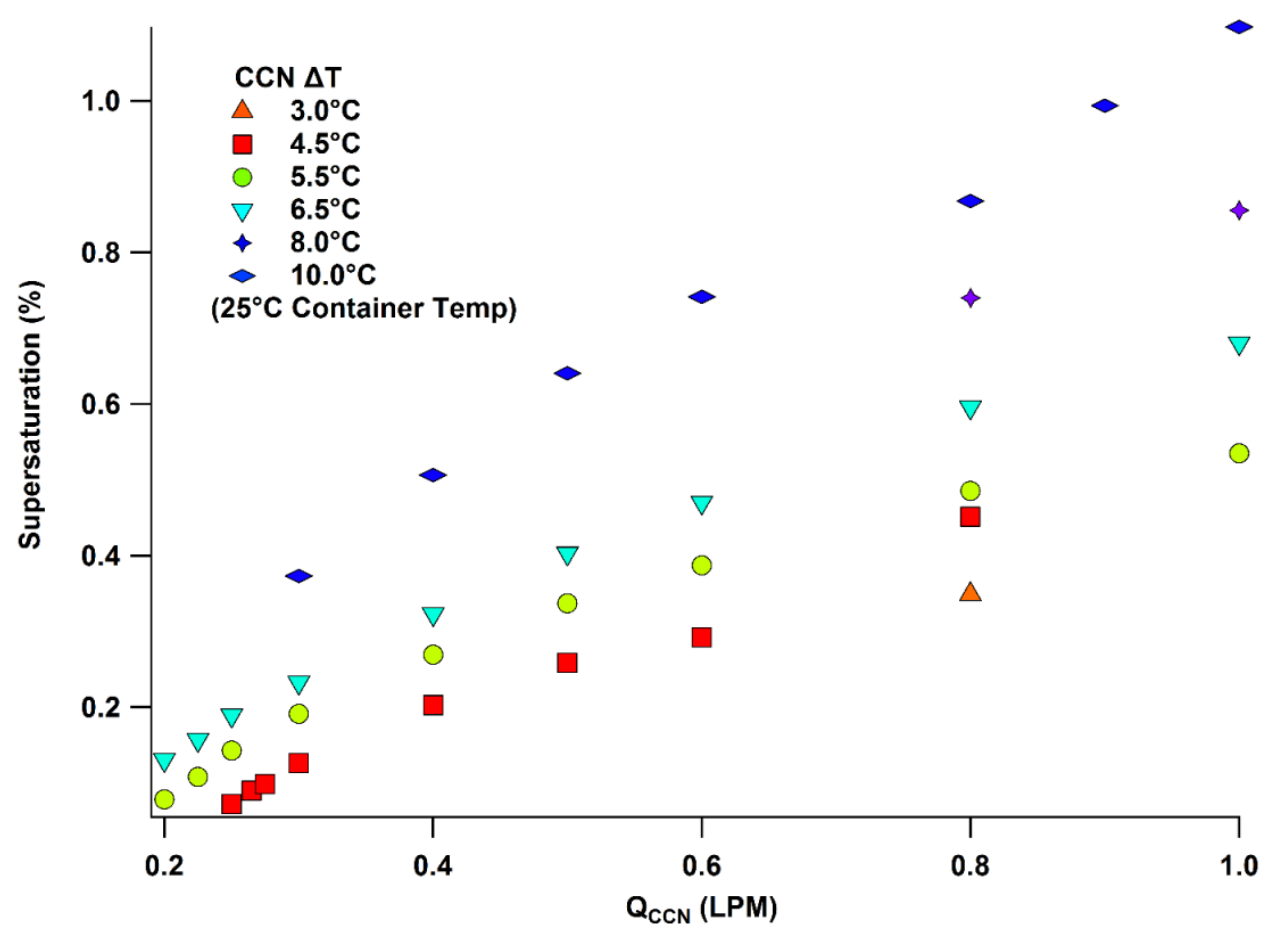

56 Figure S3: Calibrated CCN counter supersaturation as a function of $\Delta T$ at $T_{1}$ of $25^{\circ} \mathrm{C}$ for $Q_{\mathrm{CCN}}$ 57 ranging from 0.2 to $1.0 \mathrm{LPM}$. 


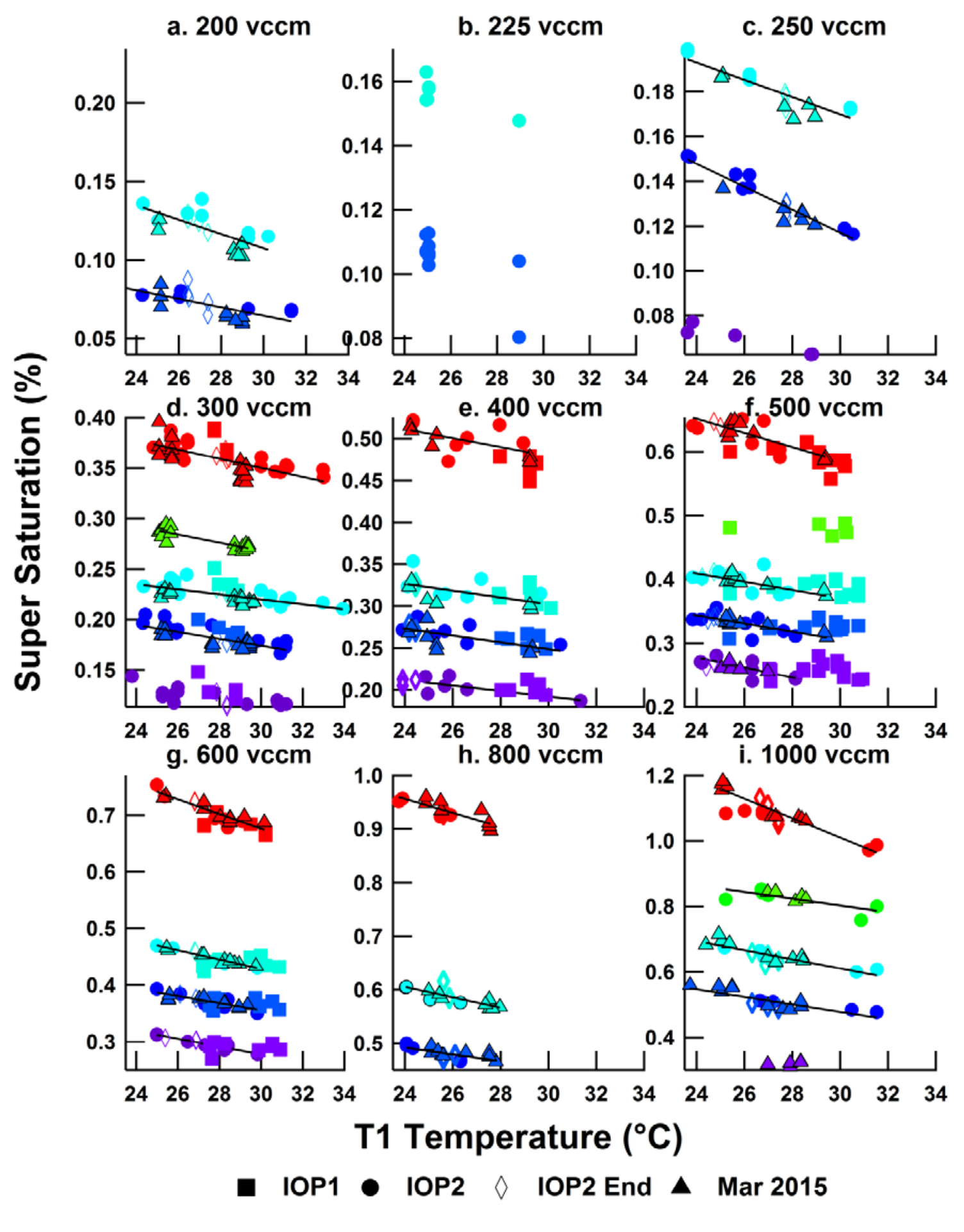

59 Figure S4: Calibrated instrument supersaturation as a function of $T_{1}$ for different $\Delta T$ and $Q_{\mathrm{CCN}}$ 60 values. The symbol colors of purple, dark blue, light blue, green and red correspond to $\Delta \mathrm{T}$ values 61 of 4.5, 5.5, 6.5, 8.0, and $10.0^{\circ} \mathrm{C}$, respectively. Calibrations were carried out throughout the entire 62 campaign (February/March 2014 - - ; August 2014 - •; October 2014 - ৩; March 2015 - $\mathbf{\Delta}$ ). The 63 lines represent least square fits of the calibration results. 


\section{ARM Facility Instruments}

\section{$65 \quad 2.1$ Measurements of Oxides of Nitrogen}

66 Oxides of nitrogen were measured by catalytic conversion to NO and chemiluminescence at

67 one minute time resolution. The $\mathrm{NO} / \mathrm{NO}_{2} / \mathrm{NO}_{\mathrm{y}}$ system is based on two Thermo Scientific 43i

68 instruments and customized by Air Quality Design, Inc. (Wheatridge, CO) for detection of NO.

69 The inlet/converter box is external and located at 10 meters above ground level and is

70 environmentally controlled. A dedicated channel converts total $\mathrm{NOy}\left(\mathrm{NO}+\mathrm{NO}_{2}+\mathrm{HNO}_{3}+\right.$

71 peroxy acyl nitrates + aerosol nitrates, but not $\mathrm{NH}_{4}$ ) to $\mathrm{NO}$ via a Mo catalyst heated to $325^{\circ} \mathrm{C}$. A

72 second channel converts $\mathrm{NO}_{2}$ to $\mathrm{NO}$ by a light emitting diode (LED) photolysis cell with 50\%

73 conversion efficiency (C.E.). The LED is toggled on and off on a two minute cycle to measure

74 ambient $\mathrm{NO}$ and $\mathrm{NO}+$ C.E. $\times \mathrm{NO}_{2}$, and the $\mathrm{NO}_{2}$ mixing ratio is derived from the difference of

75 the measurements. The inlet box contains mass flow controllers (MFCs) so that the residence

76 time to the chemiluminescence cells is minimal and occurs at reduced pressure. The unit is

77 calibrated daily with standard additions of $\mathrm{NO}$ and $\mathrm{NO}_{2}$ to measure the conversion efficiency of

78 both the Mo converter $(1.00 \pm 0.02)$ and the photolysis cell.

\subsection{Refractory Black Carbon Measurements}

80 The incandescence signal measured by SP2 is proportional to the mass of rBC in the particles

81 irrespective of whether the rBC is coated or not (Moteki et al., 2007; Schwarz et al., 2010;

82 Stephens et al., 2003). The SP2 was calibrated using size-selected fullerene soot with no

83 corrections for non-rBC content. The detectable size range of the SP2 is 75 - $600 \mathrm{~nm}$ (volume

84 equivalent diameter), which typically provides a direct measurement of $>90 \%$ of $\mathrm{rBC}$ mass

85 concentrations. If necessary, the complete mass size distribution is extrapolated to include rBC

86 outside of this size range assuming a log-normal distribution (Mei et al., 2013). During 
87 GoAmazon 2014/5, rBC mass was mostly within the detectable range. In contrast to the SP2, the

88 seven-wavelength Aethalometer (Arnott et al., 2005; Hansen et al., 1984) reports an equivalent

89 black carbon mass loading by converting a light absorption measurement from aerosols

90 accumulated on a filter relative to a manufacturer-supplied conversion. However, there is

91 substantial and growing evidence relating to measurement artifacts attributed to aerosol loading

92 effects and enhanced light absorption through multiple-scattering of photons (Collaud Coen et

93 al., 2010; Rizzo et al., 2011; Schmid et al., 2006; Virkkula et al., 2015; Virkkula et al., 2007;

94 Weingartner et al., 2003). Given the more complete dataset of the Aethalometer, our analysis

95 utilized the Aethalometer data only when SP2 data was unavailable. The available concurrent

96 SP2 and Aethalometer datasets were used to derive a linear relationship to correct for

97 Aethalometer measurement artifacts cited above. The mass concentrations of refractory black

98 carbon (rBC) derived from SP2 and Aethalometer data were averaged to a common time base

99 and the least square linear fit between both rBC mass concentrations is shown in Fig. S5 for both

100 the wet and dry seasons. The linear relationship exhibited a seasonal dependence, which might

101 be driven by variations in $\mathrm{RH}$, the ratio of mass concentrations of organics to $\mathrm{BC}$, or a 102 combination of both. The rBC mass concentration derived from the Aethalometer measurement 103 was used to fill the gaps in the SP2 data after scaled using the linear relationship corresponding 104 to the respective season. 


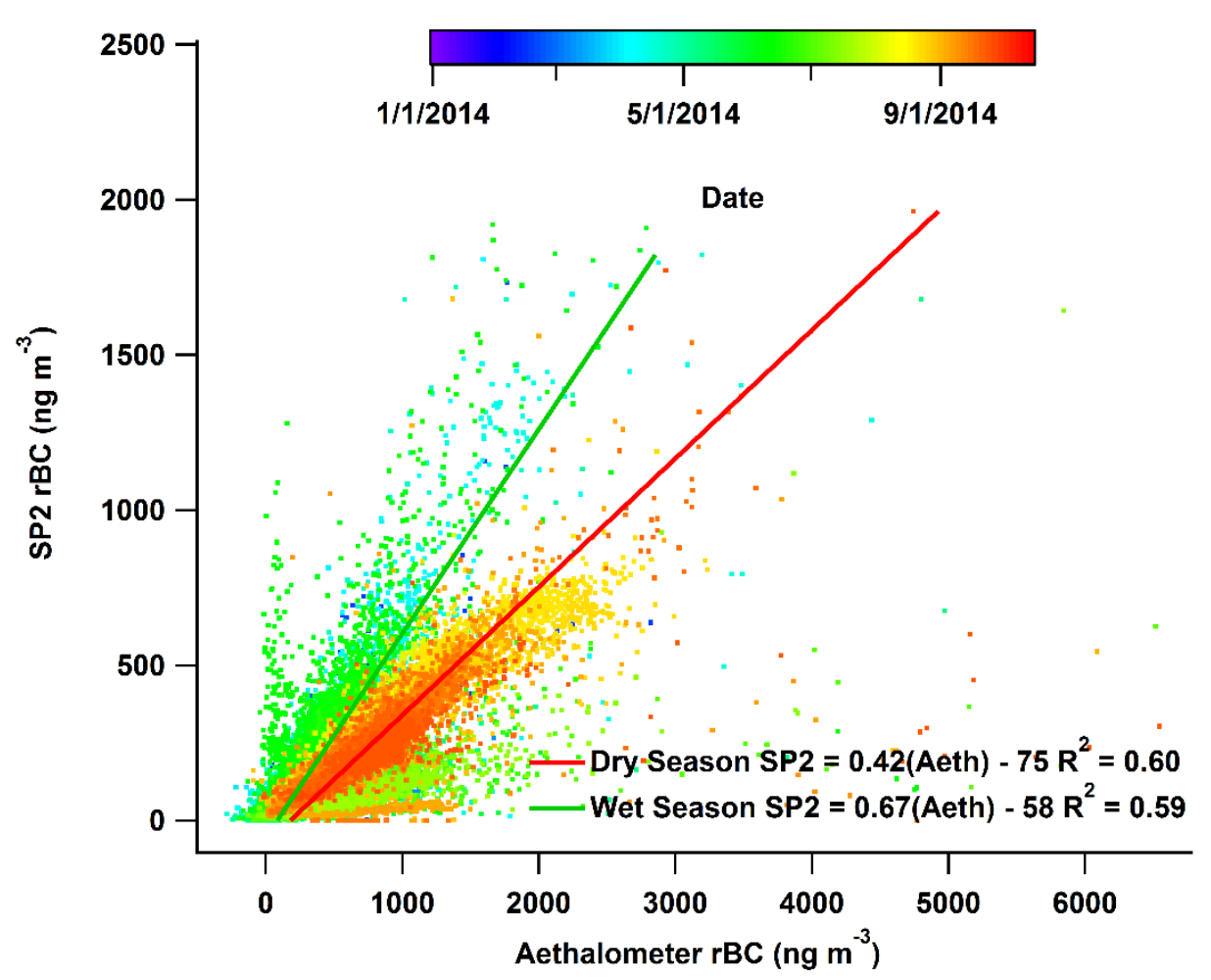

108 Figure S5: Correlation between rBC mass concentrations derived from the Aethalometer and SP2 109 measurements. Data points are colored by the time of the measurements. The red and green lines 110 represent least square fit of data collected during the dry and wet seasons, respectively.

\section{Reduction of the size resolved CCN activation spectrum}

\section{$113 \quad 3.1$ Correction for multiple charging}

114 Size-resolved CCN activation fraction was characterized at particle diameters of 51, 75, 94,

115 112, 142, 171 and $222 \mathrm{~nm}$. These sampling sizes were selected to form a progression of particle

116 diameters corresponding to doubly and triply charged particles (e.g. $112 \mathrm{~nm}$ corresponds to the

117 diameter of doubly charged particles, when the DMA is set to select particles with a diameter of

$11875 \mathrm{~nm}$. See Table S1 for more details). The contribution of doubly and triply charged particles to

119 the activation fraction was corrected using the size distribution measured by the SMPS (Model 1203080 TSI, Inc) in MAOS and particle charging probabilities (Wiedensohler, 1988). In cases 121 when the size distribution data were not available, we used the concentrations of classified 
122 particles measured by the CPC in the size-resolved CCN system when sampling at corresponding

123 multiple-charged sizes. The impact of multiple-charged particles on activation fraction was then

124 accounted for using the concentration of multiple-charged particles and the measured activation

125 fractions at the corresponding sizes. This is similar to the methods established in the literature

126 (Rose et al., 2008). When direct measurements of the activation fraction of multiple charged

127 particles were not available, the multiple charged particles were assumed to have the same

128 distribution of $\kappa$ as the singly charge particles, and the activation fraction was corrected using the

129 following iterative approach. First, the activation fractions of multiple charged particles were

130 derived from the measured activation factions, taken into consideration the same $\kappa$ distribution

131 but larger particle diameters. These derived activation fractions at multiple charged sizes were

132 then used to correct measured activation fraction using the approach described above. This

133 process was continued until the corrected activation fraction of singly charged particles

134 converged.

$136 \quad 3.2$ Data quality control criteria

137 Several quality-control criteria were applied to the data and results from the fitting of

138 activation spectrum. The measurement of the entire activation spectrum at a single particle

139 diameter took about 5-20 minutes. Individual points (i.e., activation fraction at a single $S$ ) of an

140 activation spectrum were excluded from the fitting if the standard deviation of 1-sec

141 measurements of the classified particle concentration is greater than $30 \%$ of the mean value for

142 the current size, or single data points are more than 1.5 times the mean. This is to remove large

143 fluctuation or spikes in CPC concentration due to contamination by emission of site generator or

144 traffic. The removal of measurement at single supersaturation typically does not prevent fitting 
145 of the activation spectrum using data at remaining supersaturation points. Parameters derived

146 from the fitting of activation spectrum were flagged and excluded from further analysis in this

147 study for the following scenarios:

148 1. The fitted $S^{*}$ is outside the supersaturation range of the measured activation spectrum.

1492 2. The fitted maximum activated fraction $(E)$ is not within $15 \%$ of any activated fraction

150 measured at the three highest supersaturations. This indicates that the activation fraction

151 did not reach a plateau even at the highest supersaturations sampled, and therefore $E$ is

152 not well constrained by the activation spectrum.

153 3. The residue of the fit is greater than 0.1 . This indicates relatively poor fit, which 154 represented less $1 \%$ of the activation spectra.

155 4. The fitted $E$ is less than 0.5 , indicating external mixtures with substantial fraction of fresh 156 black carbon and primary organic aerosols emitted by the generator, vehicles, and grass 157 cutting activities at or near the site.

158 For the one-year measurement period, $6.5 \%$ of the total activation curves were removed by 159 the above data quality filters.

3.4 Deriving average particle hygroscopicity and hygroscopicity dispersion from activation spectrum

163 For particles with the same size and composition (i.e., hygroscopicity), a step increase of $R_{a}$

164 from $0 \%$ to $100 \%$ with increasing supersaturation is expected because all particles would have 165 the identical critical supersaturation $\left(S_{c}\right)$. The measurements of ambient aerosols show more 166 gradual increase in $R_{\mathrm{a}}$ (i.e., instead of a step change), suggesting heterogeneity in particle $S_{\mathrm{c}}$. The 167 heterogeneity in particle $S_{\mathrm{c}}$, as described by $\sigma_{s}$ is due to a combination of width of DMA transfer 
168 function (particles classified by a DMA do not have exactly the same size), instrument non-

169 idealities, and the heterogeneity in particle hygroscopicity. The value of $\sigma_{\mathrm{s}}$ due to the

170 heterogeneity in particle hygroscopicity alone can be estimated by:

$171 \sigma_{s}=\sqrt{\sigma_{s, \mathrm{~m}}^{2}-\sigma_{s, \mathrm{AS}}^{2}}$

172 Where $\sigma_{s, \mathrm{~m}}$ and $\sigma_{\mathrm{s}, \mathrm{AS}}$ are the values corresponding to the ambient measurement and the calibration 173 using ammonium sulfate, respectively (Supplementary Information, Mei et al., 2013). Particle

174 critical supersaturation $S_{\mathrm{c}}$ is related to hygroscopicity $\kappa$ by (Petters and Kreidenweis, 2007):

175

$$
\begin{aligned}
& S_{\mathrm{c}}(\kappa)=\left(\frac{4 A^{3}}{27 D_{\mathrm{p}}^{3} \kappa}\right)^{1 / 2}, \\
& A=\frac{4 \sigma_{\mathrm{w}} M_{\mathrm{w}}}{R T \rho_{\mathrm{w}}}
\end{aligned}
$$

176 Where $D_{\mathrm{p}}$ is the particle diameter, $M_{\mathrm{w}}, \rho_{\mathrm{w}}$ and $\sigma_{\mathrm{w}}$ are the molecular weight, density and surface 177 tension of water, respectively. The probability distribution function of particle hygroscopicity $178 p(\kappa)$ can be derived as the following:

$179 p(\kappa)=-\frac{d R_{\mathrm{a}}\left(S_{\mathrm{c}}(\kappa)\right)}{d \kappa}$

180 Where $R_{\mathrm{a}}$ is the fitted active spectrum with $\sigma_{\mathrm{s}}$ adjusted using Eq. (S1). We note that Eq. (S2)

181 represents an approximation (Petters and Kreidenweis, 2007). For this study, the uncertainty of 182 derived $\kappa$ values due to this approximation is negligible. The dispersion of $\kappa$, which describes the 183 heterogeneity of hygroscopicity for activated particles, is given by (Mei et al., 2013):

$184 \sigma(\kappa) / \overline{\kappa_{\mathrm{CCN}}}=\left[\exp \left(4 \sigma_{s}^{2}\right)-1\right]^{1 / 2}$ 
185 where $\sigma(\kappa)$ and $\overline{\kappa_{\mathrm{CCN}}}$ are the standard deviation and average value of the hygroscopicity for 186 activated particles.

187 It is worth noting that because of the skewness of the lognormal distribution, the average particle

188 hygroscopicity $\overline{\kappa_{\mathrm{CCN}}}$ is higher than $\kappa^{*}$, which corresponds to the fitted $S^{*}$, and represents the 189 median hygroscopicity of activated particles (Fig. S6). The difference between $\overline{\kappa_{\mathrm{CCN}}}$ and $\kappa^{*}$ 190 becomes significant at high $\sigma_{s}$ values (Fig. S7). In this study, $\overline{\kappa_{\mathrm{CCN}}}$ is derived from the 191 probability density function using the following equation:

$192 \overline{\kappa_{\mathrm{CCN}}}=\frac{\int_{0}^{0.65} \kappa \cdot p(\kappa) d \kappa}{\int_{0}^{0.65} p(\kappa) d \kappa}$

193 The upper limit of the integration is limited to 0.65 , which reflects the maximum particle 194 hygroscopicity expected at the T3 site. The organic hygroscopicity is derived from the average 195 particle hygroscopicity $\overline{\kappa_{\mathrm{CCN}}}$ and average chemical composition. 


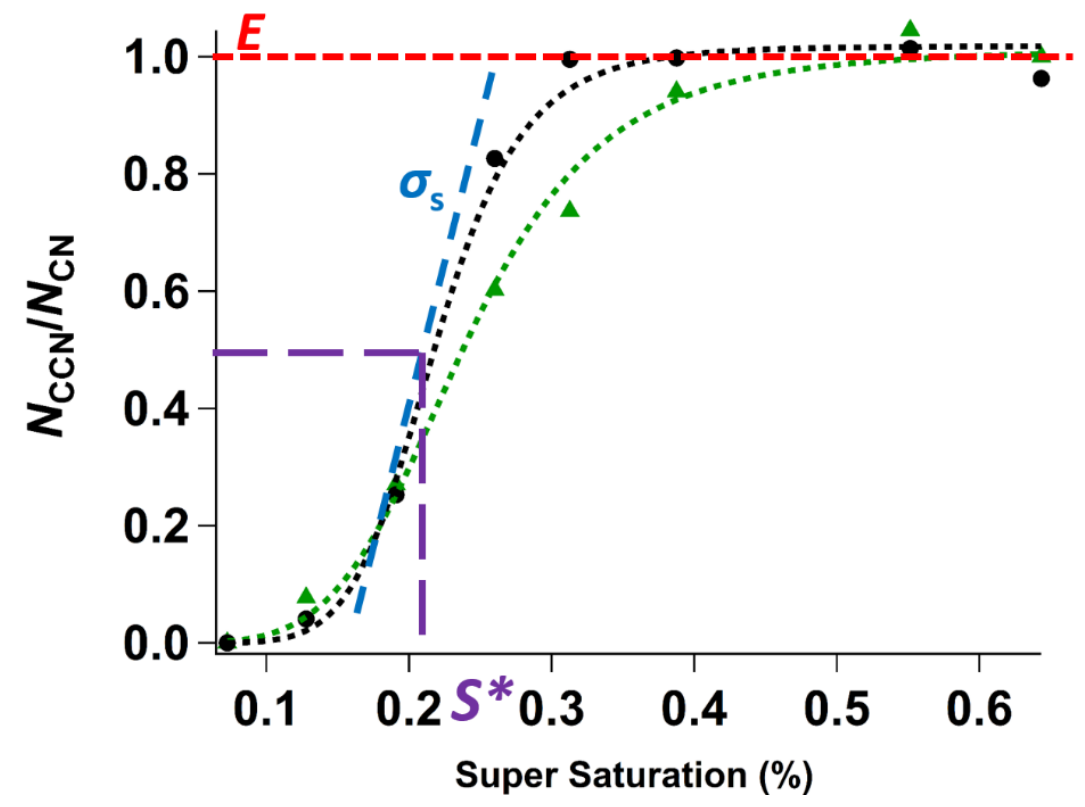

197 Figure S6: Sample activation spectra for particles with diameter of $142 \mathrm{~nm}$. The black dots and 198 green triangles represent spectra with a low dispersion $\left(\sigma_{\mathrm{s}}=0.2 ; \sigma(\kappa) / \overline{\kappa_{\mathrm{CCN}}}=0.4\right)$ and a much 199 higher dispersion $\left(\sigma_{\mathrm{s}}=0.4 ; \sigma(\kappa) / \overline{\kappa_{\mathrm{CCN}}}=0.9\right)$, respectively.

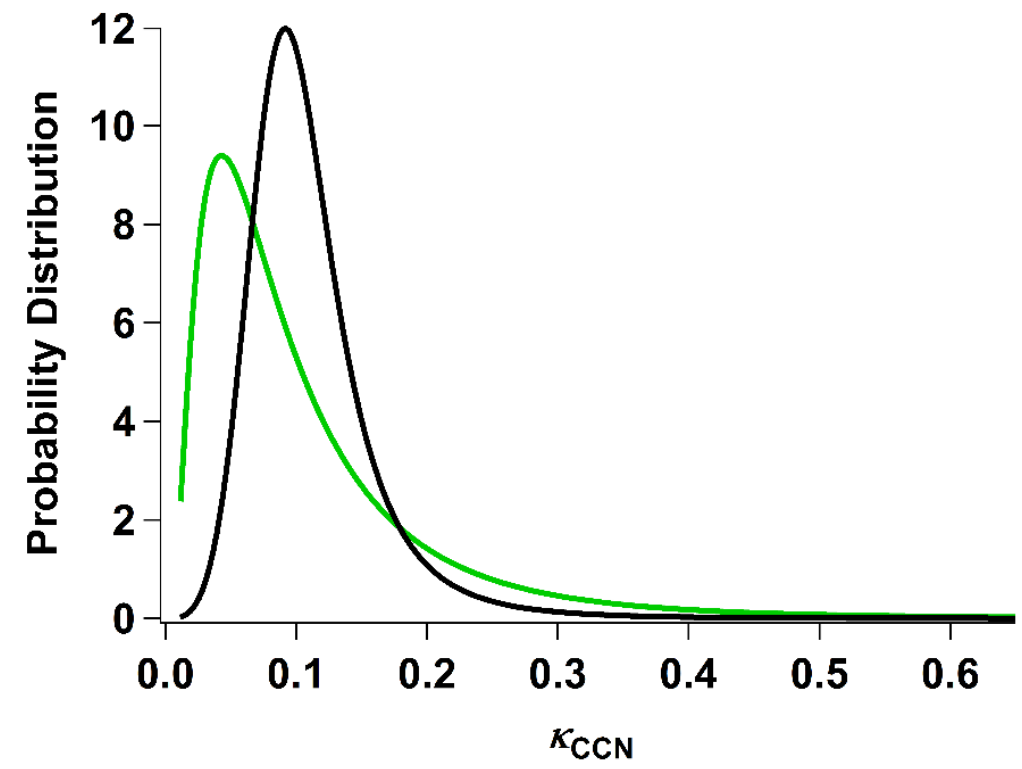

201 Figure S7: Probability density distributions of particle hygroscopicity derived from the fitted 202 activation spectra shown in Figure S6. As dispersion increases, the distribution becomes 203 increasingly asymmetric, and the difference between $\overline{\kappa_{\mathrm{CCN}}}$ and $\kappa^{*}$ increases. 


\section{Aerosol composition derived from AMS and rBC measurements}

\section{4.1 Bulk and size-resolved mass concentration of aerosol species}

206 Given the very low aerosol mass concentration in the Amazon basin, the signal to noise ratio

207 of particle time-of-flight (P-ToF) mode measurement was not sufficient to directly provide size

208 resolved species mass concentrations for individual CCN activation spectrum. Instead, the size 209 resolved species mass concentrations were constructed by combing the bulk mass concentrations 210 measured in MS mode, which have higher signal to noise ratio, and P-ToF mode size resolved 211 species mass distributions averaged over extended time periods. For both IOPs, the bulk organics

212 mass fraction was derived from MS mode portion of individual AMS measurement. Based on the

213 bulk organic mass fraction, measurements during IOP1 were then classified into three groups

214 with equal number of measurements, and the characteristic mass size distribution of each species

215 (i.e., organics, $\mathrm{SO}_{4}, \mathrm{NO}_{3}$, and $\mathrm{NH}_{4}$ ) was averaged from P-ToF measurements within each group.

216 For IOP2, the measurements were classified into three groups each for day and night periods

217 based on the bulk aerosol organic mass fraction, and the mass size distribution of each species

218 was averaged from P-ToF measurements in each of the six groups. The average mass size

219 distributions of the four species for the three groups during the daytime of IOP2 are shown in

220 Fig. S8 as examples. The underlying assumption is that observed aerosols exhibiting similar

221 bulk composition (i.e., organic mass fraction) during the IOPs also had species mass size

222 distributions with the same shapes. The vacuum aerodynamic diameter $\left(D_{\text {va }}\right)$ measured by the

223 AMS was converted to particle mobility diameter $\left(D_{\mathrm{m}}\right)$ and volume equivalent diameter $\left(D_{\mathrm{v}}\right)$

224 using the particle density with the assumption of spherical particles, which is reasonable given

225 most of the aerosol observed at T3 site were quite aged. The average densities were calculated 226 using the approach described in Kuwata et al. (2012), and were $1.45 \mu \mathrm{g} \mathrm{m}{ }^{3}$ and 1.47 during IOP

2271 and 2, respectively. In this study, unless otherwise indicated, particle diameter $D_{\mathrm{p}}$ represents 
228 the mobility diameter $\left(D_{\mathrm{m}}\right)$, which is equivalent to the volume average diameter given the 229 assumption of spherical particles.

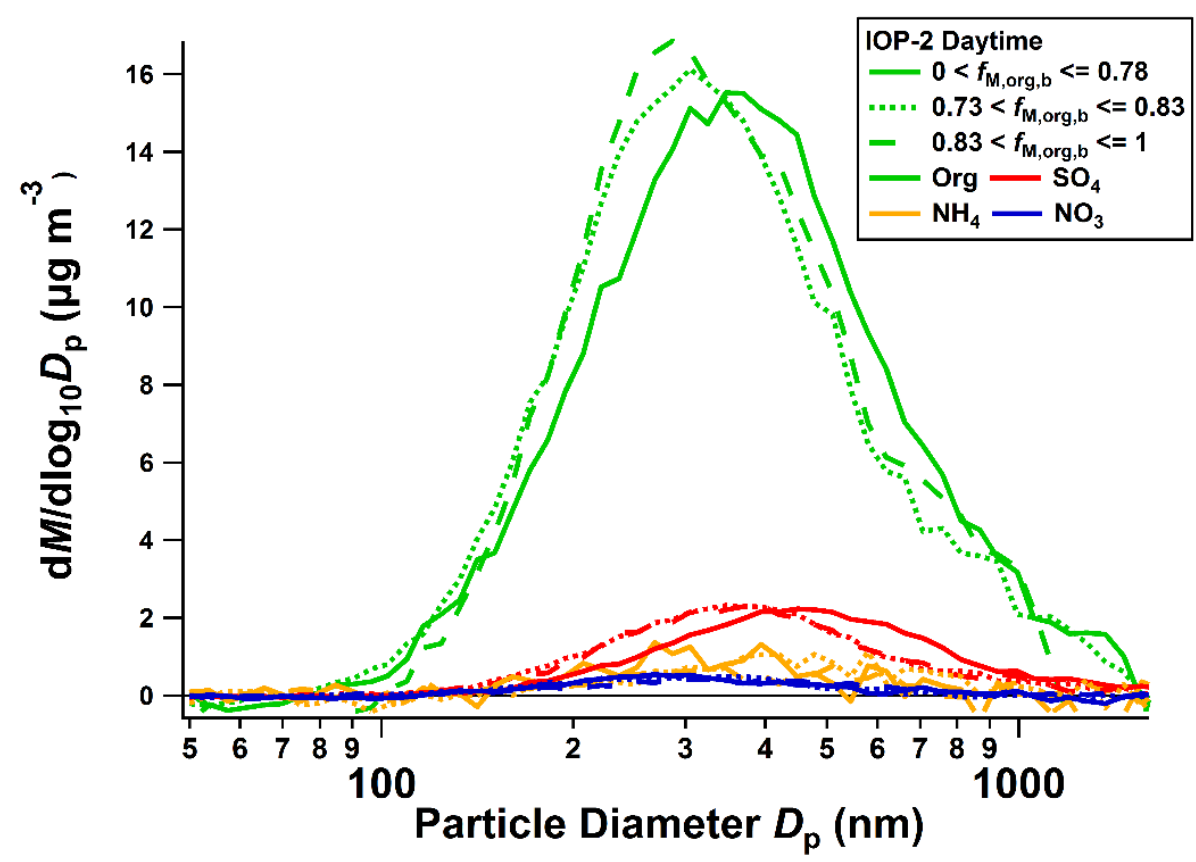

231 Figure S8: Size resolved mass concentrations of organics, $\mathrm{SO}_{4}, \mathrm{NO}_{3}$, and $\mathrm{NH}_{4}$ averaged from $\mathrm{P}$ 232 ToF measurements for each of three groups during the day time of IOP2 (dry season). The three 233 groups were classified based on bulk organics mass fraction $\left(f_{\mathrm{M}, \mathrm{org}}\right)$.

$238 m_{\text {org }}\left(D_{p}\right)=M_{\text {org }, b} \times \frac{\bar{m}_{\text {org }}\left(D_{p}\right)}{\int_{D_{p, \text { min }}}^{D_{\text {orgax }}} \bar{m}_{\text {org }}\left(D_{p}^{\prime}\right) d \log D_{p}^{\prime}}$

239 where $M_{\text {org, } b}$ is the bulk organic mass concentration from MS mode measurement, $\bar{m}_{\text {org }}\left(D_{p}\right)$ is

240 the average organic mass size distribution with respect to $\log D_{p}, D_{\mathrm{p}, \max }$ and $D_{\mathrm{p}, \min }$ are the 
241 maximum and minimum diameters of the average mass size distribution. Using the same

242 approach, the mass concentration of $\mathrm{SO}_{4}^{2-}, \mathrm{NO}_{3}^{-}$, and $\mathrm{NH}_{4}^{+}$at specific $D_{\mathrm{p}}$ are calculated using

243 the corresponding average mass size distributions. Mass concentration for black carbon

$244 m_{r B C}\left(D_{\mathrm{p}}\right)$ is derived with the assumption that the mass size distribution of rBC has the same

245 shape of the total mass size distribution:

$246 \quad f_{M, r B C}=\frac{M_{r B C, b}}{M_{\text {total }, b}}=\frac{m_{r B C}\left(D_{p}\right)}{m_{\mathrm{SO}_{4}^{2-}}\left(D_{p}\right)+m_{\mathrm{NO}_{3}^{-}}\left(D_{p}\right)+m_{\mathrm{NH}_{4}^{+}}\left(D_{p}\right)+m_{\text {org }}\left(D_{p}\right)+m_{r B C}\left(D_{p}\right)}$

247 where $f_{M, r B C}$ is the bulk mass fraction of refractory black carbon, $M_{r B C, b}$ and $M_{\text {total,b}}$ are the

248 bulk rBC and total aerosol mass concentrations, respectively. From Eq. (S7), $m_{r B C}\left(D_{p}\right)$ can be 249 derived as:

250

$m_{r B C}\left(D_{p}\right)=\frac{f_{M, r B C}\left[m_{\mathrm{SO}_{4}^{2-}}\left(D_{p}\right)+m_{\mathrm{NO}_{3}}\left(D_{p}\right)+m_{\mathrm{NH}_{4}^{+}}\left(D_{p}\right)+m_{\text {org }}\left(D_{p}\right)\right]}{\left(1-f_{M, r B C}\right)}$

251 The fractional chemical composition at the size of CCN measurement $D_{\mathrm{p}}$ was then derived from

252 the species mass concentrations calculated above. While not perfect, this approach allowed us to

253 take both the temporal variation and size dependence of species mass concentrations into

254 consideration when deriving particle composition at the sizes of CCN measurements. This is

255 important because the organic volume fraction, required to derive the organic hygroscopicity was

256 often much higher at the sizes of CCN measurements than that based on the bulk measurements. 
Outside of the IOP periods, particle composition was derived from ACSM data, and the

261 retrieval of organonitrate mass concentration is not available. In addition, the detection limit of

$262 \mathrm{NH}_{4}^{+}$for the ACSM is very high, such that the measurement of $\mathrm{NH}_{4}^{+}$mass concentration was

263 too noisy for determining aerosol ionic balance. The sensitivity of derived $\kappa_{\text {org }}$ to the assumption

264 on nitrate was examined using the AMS data from the two IOPs to inform the appropriate

265 assumptions for the analysis outside the IOP periods. Organic hygroscopicity was calculated

266 using three different approaches: (1) the approach based on the retrievals of both inorganic and

267 organic nitrate mass concentrations from AMS, as described in section 3.2 of the main text, (2)

268 all $\mathrm{NO}_{3}^{-}$was assumed from $\mathrm{NH}_{4} \mathrm{NO}_{3}$ and all sulfate from ammonium sulfate, and (3) all $\mathrm{NO}_{3}^{-}$

269 was from organonitrate with all sulfate from ammonium sulfate. $\kappa_{\text {org }}$ derived using the three

270 different assumptions are shown in Figure $\mathrm{S} 9$ for both IOPs. When all $\mathrm{NO}_{3}^{-}$is assumed from

271 organonitrate (i.e., approach 3), the derived $\kappa_{\text {org }}$ values are very close to those based on retrieved

272 organonitrate and inorganic nitrate concentrations from AMS data (i.e., approach 1). As a result,

273 for measurements outside of the two IOPs when only ACSM measurements are available, all

274 measured $\mathrm{NO}_{3}^{-}$was assumed from organonitrate and sulfate was assumed from ammonium 275 sulfate. 


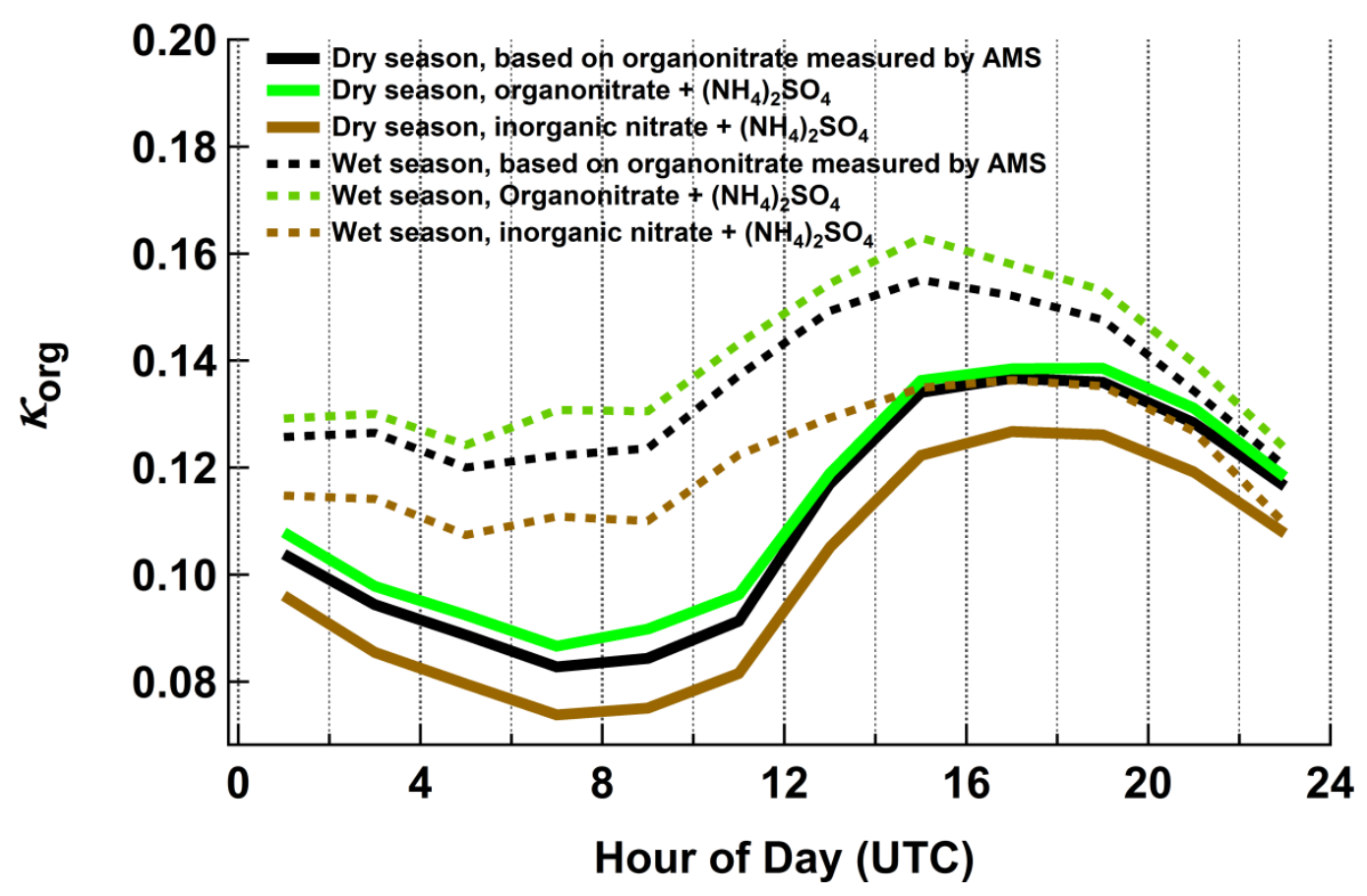

278 Figure S9: Diel variations of organic hygroscopicity derived using the three different 279 assumptions on nitrate described in the text (i.e., mixed inorganic/organic nitrates, all organic 280 nitrate, and all inorganic nitrate). 


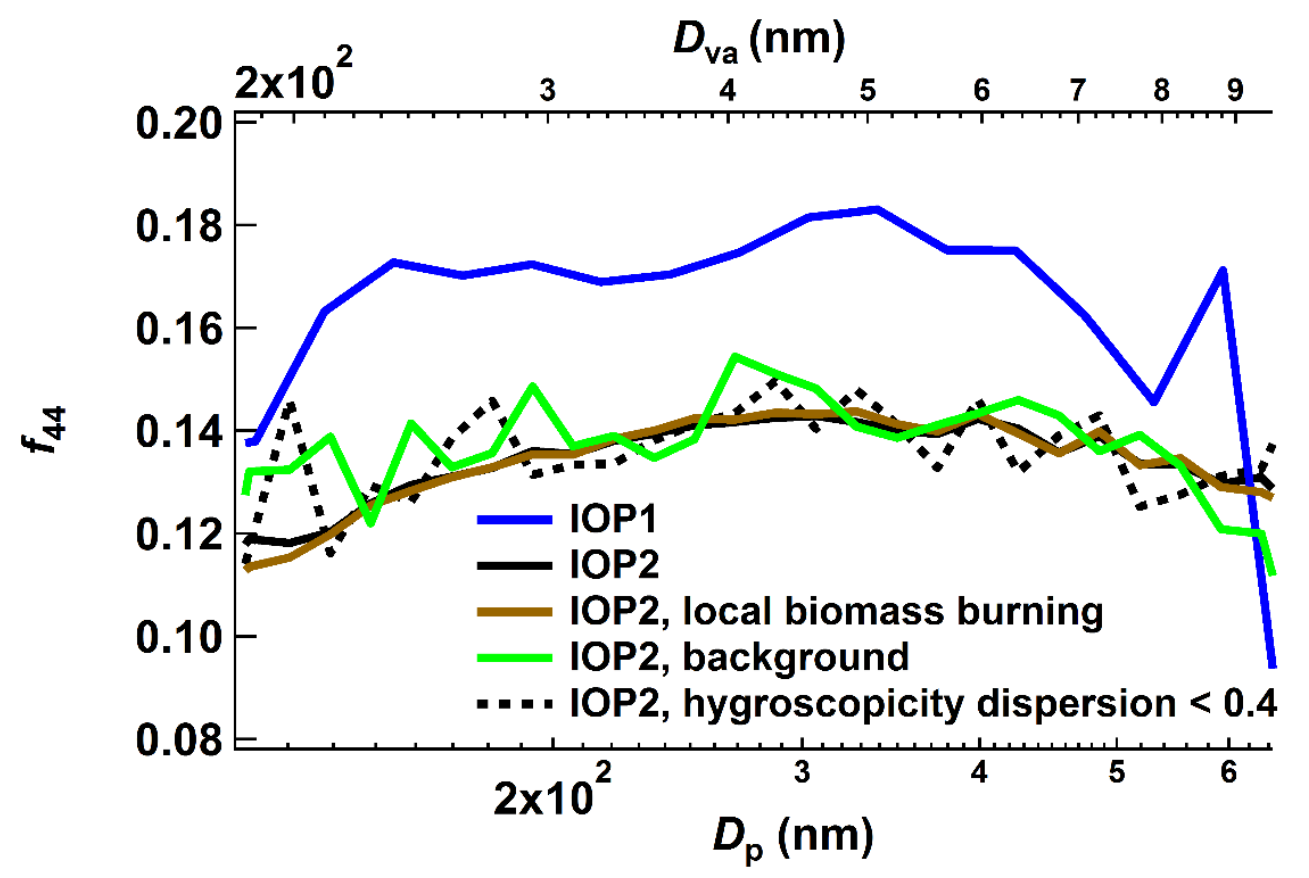

283 Figure S10: Size dependence of the fraction of the organic mass at $\mathrm{m} / \mathrm{z}=44\left(f_{44}\right)$, which is 284 indicative of the extent of oxidation. The $f_{44}$ averaged during IOP1 was essentially independent 285 of particle diameter $D_{\mathrm{p}}$ from 140 to $400 \mathrm{~nm}$, a size range that dominated bulk organic mass 286 concentration and encompasses the diameters of CCN measurements (i.e., 142 and $171 \mathrm{~nm}$ ). 287 During the IOP2, $f_{44}$ averaged for all data and local biomass burning air mass type showed a clear 288 dependence on $D_{\mathrm{p}}$. In comparison, $f_{44}$ averaged for the background condition and the periods 289 with low hygroscopicity dispersion $\left(\sigma_{\bar{\kappa}} / \bar{\kappa}<0.4\right)$ during IOP2 had lower signal to noise ratio due 290 to the low mass loading, but were largely independent of particle size. 


\section{Tables}

293 Table S1: Particle diameter classified by the DMA and the corresponding diameters for doubly 294 and triply charged particles. Diameters in the parenthesis represent the measurements (if 295 available) used to correct the contribution of doubly and triply charged particles to the measured 296 activation fractions.

\begin{tabular}{ccc}
\hline $\begin{array}{c}\text { DMA classified singly } \\
\text { charged particles, } D_{\mathrm{p}}(\mathrm{nm})\end{array}$ & $\begin{array}{c}\text { Doubly charged } \\
\text { particles } D_{\mathrm{p}}(\mathrm{nm})\end{array}$ & $\begin{array}{c}\text { Triply charged } \\
\text { particles } D_{\mathrm{p}}(\mathrm{nm})\end{array}$ \\
\hline 51 & $75(75)$ & $94(94)$ \\
75 & $112(112)$ & $142(142)$ \\
94 & $142(142)$ & $182(171)$ \\
112 & $171(171)$ & $222(222)$ \\
142 & $221(222)$ & $293(\mathrm{~N} / \mathrm{A})$ \\
171 & $272(\mathrm{~N} / \mathrm{A})$ & $365(\mathrm{~N} / \mathrm{A})$ \\
222 & $364(\mathrm{~N} / \mathrm{A})$ & $498(\mathrm{~N} / \mathrm{A})$ \\
\hline
\end{tabular}


Table S2: Criteria used to classify air mass type for different seasons. The threshold values of CN and $\mathrm{CO}$ concentrations used to identify background conditions are the mean plus one standard deviation

302 of respective measurements at the background sites T0a and T0t.

\begin{tabular}{|c|c|c|c|c|}
\hline \multirow{2}{*}{ Air mass type } & \multicolumn{4}{|c|}{ Season } \\
\hline & Wet/Wet 2 & Transition 1 & Dry & Transition 2 \\
\hline Background & $\begin{array}{l}\mathrm{CN}<500 \mathrm{~cm}^{-3} \\
\mathrm{CO}<0.14 \mathrm{ppm} \\
\mathrm{NO}_{\mathrm{y}}<1.5 \mathrm{ppbv}\end{array}$ & $\begin{array}{l}\mathrm{CN}<900 \mathrm{~cm}^{-3} \\
\mathrm{CO}<0.14 \mathrm{ppm} \\
\mathrm{NO}_{\mathrm{y}}<1.5 \mathrm{ppbv}\end{array}$ & $\begin{array}{l}\mathrm{CN}<1500 \mathrm{~cm}^{-3} \\
\mathrm{NO}_{\mathrm{y}}<1.5 \mathrm{ppbv}\end{array}$ & $\begin{array}{l}\mathrm{CN}<1500 \mathrm{~cm}^{-3} \\
\mathrm{NO}_{\mathrm{y}}<1.5 \mathrm{ppbv}\end{array}$ \\
\hline $\begin{array}{l}\text { Urban } \\
\text { Pollution }\end{array}$ & $\begin{array}{c}\mathrm{CN}>500 \mathrm{~cm}^{-3} \\
* f_{<70}>0.45\end{array}$ & $\begin{array}{c}\mathrm{CN}>900 \mathrm{~cm}^{-3} \\
f_{<70}>0.45\end{array}$ & $\begin{array}{c}\mathrm{CN}>1500 \mathrm{~cm}^{-3} \\
f_{<70}>0.45\end{array}$ & $\begin{array}{c}\mathrm{CN}>1500 \mathrm{~cm}^{-3} \\
f_{<70}>0.45\end{array}$ \\
\hline $\begin{array}{l}\text { Local biomass } \\
\text { burning }\end{array}$ & $\begin{array}{c}\mathrm{CN}>500 \mathrm{~cm}^{-3} \\
f_{<70}<0.45 \\
\mathrm{CO}>0.14 \mathrm{ppm}\end{array}$ & $\begin{array}{c}\mathrm{CN}>900 \mathrm{~cm}^{-3} \\
f_{<70}<0.45 \\
\mathrm{CO}>0.14 \mathrm{ppm}\end{array}$ & $\begin{array}{c}\mathrm{CN}>1500 \mathrm{~cm}^{-3} \\
f_{<70}<0.45\end{array}$ & $\begin{array}{c}\mathrm{CN}>1500 \mathrm{~cm}^{-3} \\
f_{<70}<0.45\end{array}$ \\
\hline $\begin{array}{l}\text { Site } \\
\text { Contamination }\end{array}$ & $\begin{array}{l}\mathrm{BC}>1 \mu \mathrm{g} \mathrm{m}^{-3} \\
\mathrm{CN}>10^{4} \mathrm{~cm}^{-3}\end{array}$ & $\begin{array}{l}\mathrm{BC}>1 \mu \mathrm{g} \mathrm{m}^{-3} \\
\mathrm{CN}>10^{4} \mathrm{~cm}^{-3}\end{array}$ & $\begin{array}{l}\mathrm{BC}>1 \mu \mathrm{g} \mathrm{m}^{-3} \\
\mathrm{CN}>10^{4} \mathrm{~cm}^{-3}\end{array}$ & $\begin{array}{l}\mathrm{BC}>1 \mu \mathrm{g} \mathrm{m}^{-3} \\
\mathrm{CN}>10^{4} \mathrm{~cm}^{-3}\end{array}$ \\
\hline
\end{tabular}


317 Table S3: Classification of air masses for size resolved CCN measurements at 112, 142, and 171 $318 \mathrm{~nm}$, and relevant measurements (CN, CO, SMPS, rBC) averaged to 5-min intervals.

\begin{tabular}{|c|c|c|c|}
\hline \multirow[b]{2}{*}{ Season } & \multirow[b]{2}{*}{ Classification } & \multicolumn{2}{|c|}{ Percentage of air mass types } \\
\hline & & Size resolved CCN & $\begin{array}{c}\text { Relevant } \\
\text { measurements }\end{array}$ \\
\hline \multirow{6}{*}{$\begin{array}{l}\text { Wet Season } \\
2014\end{array}$} & Background & $10.2 \%$ & $17.5 \%$ \\
\hline & Urban Pollution & $65.1 \%$ & $63.7 \%$ \\
\hline & Local Biomass Burning & $0.7 \%$ & $0.6 \%$ \\
\hline & Site Contamination & $1.1 \%$ & $1.3 \%$ \\
\hline & Invalid CCN spectra Fit ${ }^{\#}$ & $12.5 \%$ & N/A \\
\hline & Unclassified $^{\$}$ & $10.5 \%$ & $17.0 \%$ \\
\hline \multirow{6}{*}{$\begin{array}{l}\text { Transition } \\
\text { Season } 1\end{array}$} & Background & $8.9 \%$ & $11.8 \%$ \\
\hline & Urban Pollution & $59.2 \%$ & $59.1 \%$ \\
\hline & Local Biomass Burning & $3.4 \%$ & $3.6 \%$ \\
\hline & Site Contamination & $1.0 \%$ & $1.2 \%$ \\
\hline & Invalid CCN spectra Fit ${ }^{\#}$ & $4.0 \%$ & N/A \\
\hline & Unclassified $^{\$}$ & $23.6 \%$ & $24.2 \%$ \\
\hline \multirow{6}{*}{ Dry Season } & Background & $7.9 \%$ & $9.7 \%$ \\
\hline & Urban Pollution & $14.4 \%$ & $16.4 \%$ \\
\hline & Local Biomass Burning & $68.1 \%$ & $58.6 \%$ \\
\hline & Site Contamination & $1.3 \%$ & $1.1 \%$ \\
\hline & Invalid CCN spectra Fit ${ }^{\#}$ & $2.9 \%$ & N/A \\
\hline & Unclassified $^{\$}$ & $5.5 \%$ & $14.3 \%$ \\
\hline \multirow{6}{*}{$\begin{array}{l}\text { Transition } \\
\text { Season } 2\end{array}$} & Background & $26.5 \%$ & $26.9 \%$ \\
\hline & Urban Pollution & $11.0 \%$ & $10.1 \%$ \\
\hline & Local Biomass Burning & $50.4 \%$ & $53.8 \%$ \\
\hline & Site Contamination & $1.7 \%$ & $2.0 \%$ \\
\hline & Invalid CCN spectra Fit & $3.3 \%$ & N/A \\
\hline & Unclassified $^{\$}$ & $7.0 \%$ & $7.3 \%$ \\
\hline \multirow{6}{*}{$\begin{array}{l}\text { Wet Season } \\
2015\end{array}$} & Background & $8.1 \%$ & $12.6 \%$ \\
\hline & Urban Pollution & $39.6 \%$ & $41.2 \%$ \\
\hline & Local Biomass Burning & $25.6 \%$ & $24.5 \%$ \\
\hline & Site Contamination & $0.8 \%$ & $0.9 \%$ \\
\hline & Invalid CCN spectra Fit & $8.3 \%$ & N/A \\
\hline & Unclassified $^{\$}$ & $17.6 \%$ & $20.8 \%$ \\
\hline \multirow{6}{*}{$\begin{array}{l}\text { Mar } 2014 \text { - } \\
\text { Mar } 2015\end{array}$} & Background & $12.4 \%$ & $16.5 \%$ \\
\hline & Urban Pollution & $38.5 \%$ & $41.2 \%$ \\
\hline & Local Biomass Burning & $28.4 \%$ & $24.7 \%$ \\
\hline & Site Contamination & $1.2 \%$ & $1.3 \%$ \\
\hline & Invalid CCN spectra Fit & $6.5 \%$ & N/A \\
\hline & Unclassified $^{\$}$ & $13.0 \%$ & $16.3 \%$ \\
\hline
\end{tabular}


$320 \quad$ \# An invalid fit of the CCN actiation spectrum (Sec. S3.2)

321 \$ne or more of the measurements (CN, SMPS, CO, $\mathrm{rBC}$ ) neede to classify air mass is missing 322 or air mass is not classifed as one of the four types using the the criteria described in Table S2. 
324

Arnott, W. P., Hamasha, K., Moosmüller, H., Sheridan, P. J., and Ogren, J. A.: Towards Aerosol Light-Absorption Measurements with a 7-Wavelength Aethalometer: Evaluation with a Photoacoustic Instrument and 3-Wavelength Nephelometer, Aerosol Science and Technology, 39, 17-29, 2005.

Collaud Coen, M., Weingartner, E., Apituley, A., Ceburnis, D., Fierz-Schmidhauser, R., Flentje, H., Henzing, J. S., Jennings, S. G., Moerman, M., Petzold, A., Schmid, O., and Baltensperger, U.: Minimizing light absorption measurement artifacts of the Aethalometer: evaluation of five correction algorithms, Atmos. Meas. Tech., 3, 457-474, 2010.

Hansen, A. D. A., Rosen, H., and Novakov, T.: The aethalometer - An instrument for the realtime measurement of optical absorption by aerosol particles, Science of The Total Environment, 36, 191-196, 1984.

Kuwata, M., Zorn, S. R., and Martin, S. T.: Using Elemental Ratios to Predict the Density of Organic Material Composed of Carbon, Hydrogen, and Oxygen, Environmental Science \& Technology, 46, 787-794, 2012.

Lance, S., Nenes, A., Medina, J., and Smith, J. N.: Mapping the Operation of the DMT Continuous Flow CCN Counter, Aerosol Science and Technology, 40, 242-254, 2006.

Mei, F., Hayes, P. L., Ortega, A., Taylor, J. W., Allan, J. D., Gilman, J., Kuster, W., de Gouw, J., Jimenez, J. L., and Wang, J.: Droplet activation properties of organic aerosols observed at an urban site during CalNex-LA, Journal of Geophysical Research: Atmospheres, 118, 2903-2917, 2013.

Moteki, N., Kondo, Y., Miyazaki, Y., Takegawa, N., Komazaki, Y., Kurata, G., Shirai, T., Blake, D. R., Miyakawa, T., and Koike, M.: Evolution of mixing state of black carbon particles: Aircraft measurements over the western Pacific in March 2004, Geophys. Res. Lett., 34, L11803 2007.

Petters, M. D. and Kreidenweis, S. M.: A single parameter representation of hygroscopic growth and cloud condensation nucleus activity, Atmos. Chem. Phys., 7, 1961-1971, 2007.

Rizzo, L. V., Correia, A. L., Artaxo, P., Procopio, A. S., and Andreae, M. O.: Spectral dependence of aerosol light absorption over the Amazon Basin, Atmos. Chem. Phys., 11, 88998912, 2011.

Roberts, G. C. and Nenes, A.: A Continuous-Flow Streamwise Thermal-Gradient CCN Chamber for Atmospheric Measurements, Aerosol Science and Technology, 39, 206-221, 2005.

Rose, D., Gunthe, S. S., Mikhailov, E., Frank, G. P., Dusek, U., Andreae, M. O., and Poschl, U.: Calibration and measurement uncertainties of a continuous-flow cloud condensation nuclei counter (DMT-CCNC): CCN activation of ammonium sulfate and sodium chloride aerosol particles in theory and experiment, Atmos. Chem. Phys., 8, 1153-1179, 2008. 
359 Schmid, O., Artaxo, P., Arnott, W. P., Chand, D., Gatti, L. V., Frank, G. P., Hoffer, A., 360 Schnaiter, M., and Andreae, M. O.: Spectral light absorption by ambient aerosols influenced by 361 biomass burning in the Amazon Basin. I: Comparison and field calibration of absorption 362 measurement techniques, Atmos. Chem. Phys., 6, 3443-3462, 2006.

363 Schwarz, J. P., Spackman, J. R., Gao, R. S., Perring, A. E., Cross, E., Onasch, T. B., Ahern, A., 364 Wrobel, W., Davidovits, P., Olfert, J., Dubey, M. K., Mazzoleni, C., and Fahey, D. W.: The 365 Detection Efficiency of the Single Particle Soot Photometer, Aerosol Sci. Technol., 44, 612-628, 3662010.

367 Shilling, J. E., King, S. M., Mochida, M., Worsnop, D. R., and Martin, S. T.: Mass Spectral 368 Evidence That Small Changes in Composition Caused by Oxidative Aging Processes Alter 369 Aerosol CCN Properties, The Journal of Physical Chemistry A, 111, 3358-3368, 2007.

370 Stephens, M., Turner, N., and Sandberg, J.: Particle identification by laser-induced 371 incandescence in a solid-state laser cavity, Appl. Optics, 42, 3726-3736, 2003.

372 Virkkula, A., Chi, X., Ding, A., Shen, Y., Nie, W., Qi, X., Zheng, L., Huang, X., Xie, Y., Wang, 373 J., Petaja, T., and Kulmala, M.: On the interpretation of the loading correction of the 374 aethalometer, Atmos. Meas. Tech., 8, 4415-4427, 2015.

375 Virkkula, A., Mäkelä, T., Hillamo, R., Yli-Tuomi, T., Hirsikko, A., Hämeri, K., and Koponen, I. 376 K.: A Simple Procedure for Correcting Loading Effects of Aethalometer Data, Journal of the Air 377 \& Waste Management Association, 57, 1214-1222, 2007.

378 Weingartner, E., Saathoff, H., Schnaiter, M., Streit, N., Bitnar, B., and Baltensperger, U.: 379 Absorption of light by soot particles: determination of the absorption coefficient by means of 380 aethalometers, Journal of Aerosol Science, 34, 1445-1463, 2003.

381 Wiedensohler, A.: An approximation of the bipolar charge distribution for particles in the 382 submicron range, J. Aerosol Sci., 19, 387-390, 1988. 